\title{
Regenerative capacity of autologous stem cell transplantation in elderly: a report of biomedical outcomes
}

The occurrence of chronic diseases such as neurological, metabolic and cardiovascular degenerative disorders increases with age. Cell therapy is an emerging approach to the treatment of these conditions. Of particular interest is the application of autologous stem cells because it eliminates post-transplantation immune rejection and there are less ethical concerns associated with their use. The regenerative capacity of stem cells harvested from elderly people is however controversial. In this review, we analyze if self-renewal potential, differentiation capability and expression of stemness genes in stem cells collected from elderly patients validate their application in clinical trials and examine the results.

First draft submitted: 15 April 2016; Accepted for publication: 12 January 2017; Published online: 21 February 2017

Keywords: adult stem cells $\bullet$ aging $\bullet$ autologous transplantation $\bullet$ clinical trial $\bullet$ elderly patients

Stem cells are found not only in embryonic or fetal tissues but also in all adult tissues in relatively high numbers. These cells are committed to tissue repair throughout adult life. Although the number of cells and their capabilities decrease over time, rich stem cell niches remain such as bone marrow and adipose tissue [1-5].

The observation that stem cells differentiate into several cell lineages reveals their potential for use in regenerative medicine. More importantly, stem cells harvested from adult tissue can be used for autologous transplantation and can also avoid immunological rejection. However, whether stem cells from elderly people have similar capabilities as those found in younger people is yet unknown.

Some studies suggest that elderly people have fewer stem cells and that they have lost their capacity for growth and differentiation in vitro. This review focuses on determining whether stem cells from elderly people have the same capabilities as those from younger people of replacing those cells that are missing due to a degenerative disease.

Some evidence indicates that sufficient numbers of stem cells remain throughout adult life [6-8], providing an alternative for use in cell therapy.

\section{Self-renewal capability}

Self-renewal in vitro is one of the main stem cell characteristics that occur after harvest. Healthy adult stem cells grown in vitro have a high proliferation capacity. However, stem cells from elderly subjects show less proliferation potential [9]. Several studies have reported a decrease in the number of colony forming units in mesenchymal stem cell (MSC) cultures from donors aged $\geq 40$ years [10-17]. In vitro doubling times are longer in cells taken from elderly patients than those from younger donors [14] and show a substantial decrease in proliferation rate $[18,19]$.

Similar observations have been reported for lipoaspirate samples obtained from adipose tissue. In vitro doubling times dif-
Maria Teresa GonzalezGarza $^{*, \ldots, 1}$ \& Delia Elva Cruz-Vega ${ }^{\ddagger, 1}$

'Tecnologico de Monterrey, Escuela Nacional de Medicina, Morones Prieto 3000 Pte, CP64710, Monterrey, Mexico *Author for correspondence:

Tel.: +52 8188882145

Fax: +528188882052 mtgonzalezgarza@itesm.mx

${ }^{\ddagger}$ Authors contributed equally

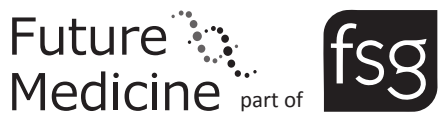


fer depending on donor age and are longer in those collected from older donors $[7,8,11]$. The relationship between the decrease in number and functionality of stem cells could be a consequence of the loss of proper environmental signals [20]. In addition, decreased telomere length and an increased rate of apoptosis and its signals have been reported in MSCs harvested from elderly donors $[12,19]$.

In addition, the definition of MSCs requires the presence of specific cell membrane antigens, such as CD73, CD90, CD105 and a lack of CD45, CD14 or CD11b, CD79a and CD19, as well as human leukocyte antigen class II. This minimal criterion was established by the Tissue Stem Cell Committee of the International Society for Cellular Therapy [21]. Until now, flow cytometry has been performed on MSCs from younger and elderly patients to confirm the presence or absence of these specific stem cell markers $[7,8]$. The overall conclusions from these reports are that MSCs from elderly donors have less capability to grow.

\section{Expression of stemness genes}

Differential expression of stemness genes on MSCs from elderly donors may be ultimately responsible for the decline of the stem cell proliferation rate. Stemness genes characterized in bone marrow-derived stem cells from patients with amyotrophic lateral sclerosis (ALS) show decreased expression of two genes related with pluripotential for the transcription factors OCT4 and NANOG. In addition, decreased expression of trophic factors, such as ANG, FGF-2, HGF, IGF-1, PIGF, SDF-1 $\alpha$, TGF- $\beta$ and VEGF, have been reported, whereas the expression of BDNF or ECGF does not decrease [17,22,23].

Similar observations have been reported for adiposederived stem cells (ADSCs) from healthy patients aged from 50 to 60 years bearing the $\mathrm{CD} 271^{+}$membrane receptor and the expression of NANOG, OCT4 and SOX2 is significantly lower than that in younger patients [7].

However, Choumerianou et al. reported no difference in the expression of NANOG or OCT4 between MSCs isolated from the bone marrow of children and those obtained from adults [24]. This observation was later confirmed by Siegel et al. in a study of PRDM14 expression, which is another gene involved in cell pluripotency [17].

Despite these controversial reports, the general consensus supports that the expression of stemness genes is lower, but their activity is sufficient for growth and self-renewal.

\section{In vitro differentiation}

Several studies have shown that healthy adult stem cells grown under specific culture conditions will differenti- ate into various cell lineages in vitro. For example, bone marrow aspirates taken from subjects aged from 19 to 57 years respond positively to induced differentiation into adipocytes, osteoblasts and chondroblasts in vitro, but some colonies display limited differentiation [25]. This result was interpreted as a loss of multilineage differentiation capability or restricted differentiation potential as a consequence of clonal cell isolation. Those authors did not analyze donor age, which could be responsible for the differences. The authors also reported decreased osteogenic differentiation potential of these cells during aging in humans. MSCs obtained from the vertebral bodies of the thoracic and lumbar spine differentiate in vitro, suggesting that the number of MSCs with osteogenic potential decreases substantially with age in humans $[8,26]$. In addition, an agedependent decrease in proliferation and differentiation into osteoblasts has been reported due to an increase in the number of senescence-associated $\beta$-galactosidasepositive cells and apoptosis in MSCs [19]. Intrinsic age-related alterations in signaling responses to osteoanabolic agents, such as parathyroid hormone (PTH), have been reported [27].

The bone-forming capacity is similar in cells obtained from younger and older donors. One hypothesis proposes that the senescence-associated decrease in bone formation is due to a defect in the bone microenvironment $[12,13]$. Chondrogenic differentiation is also controversial, as some studies have shown independent age-related responses or reduced capacity with age $[6,18]$.

Bossolasco et al. reported a significant age-related diminished response of stem cells from patients with ALS aged from 37 to 78 years. In that report, MSCs obtained from the bone marrow showed a decreased response to in vitro adipogenic and osteoblastic induction. These authors also reported a fewer number of colony forming units but no differences in the clonogenic assays between patients with ALS and healthy donors aged from 26 to 38 years [28]. These results agree with the study by Ferrero et al., who demonstrated that MSCs from healthy donors and patients with ALS (aged from 21 to 75 years) have similar osteogenic, adipogenic, chondrogenic and neurogenic differentiation potential [29]. However, another study reported that stem cells from patients with ALS (aged from 42 to 77 years) have dissimilar differentiation kinetics into the neuronal lineage but are still capable of responding to external factors and started to differentiate into a neurological lineage [22]. In contrast, the neuroectodermal differentiation potential of MSCs derived from elderly donors is completely lost [30]. ADSCs from 53 patients (aged from 50 to 89 years) revealed that elderly donors have many cells that retain a significant capacity to acquire the endothelial lineage [31]. 
Other stem cell sources, such as muscle-derived stem cells obtained from young (age 9 years) and old (age $\geq 60$ years) humans, replicated 20 - to 30 -times in vitro and differentiated into different tissue lineages. These cells (satellite cells) are found in aged human skeletal muscle and are capable of regeneration [32-34].

Stem cells from elderly donors do not have as much pluripotential as cells from younger donors. Neverthe- less, these cells are capable of self-renewal and differentiation into osteoblasts, chondroblasts, adipocytes and other cell lineages (Figure 1).

\section{Clinical reports}

Samples of pluripotent stem cells for autologous transplantation have been obtained from several tissues of differently aged donors. The most abundant and rela-

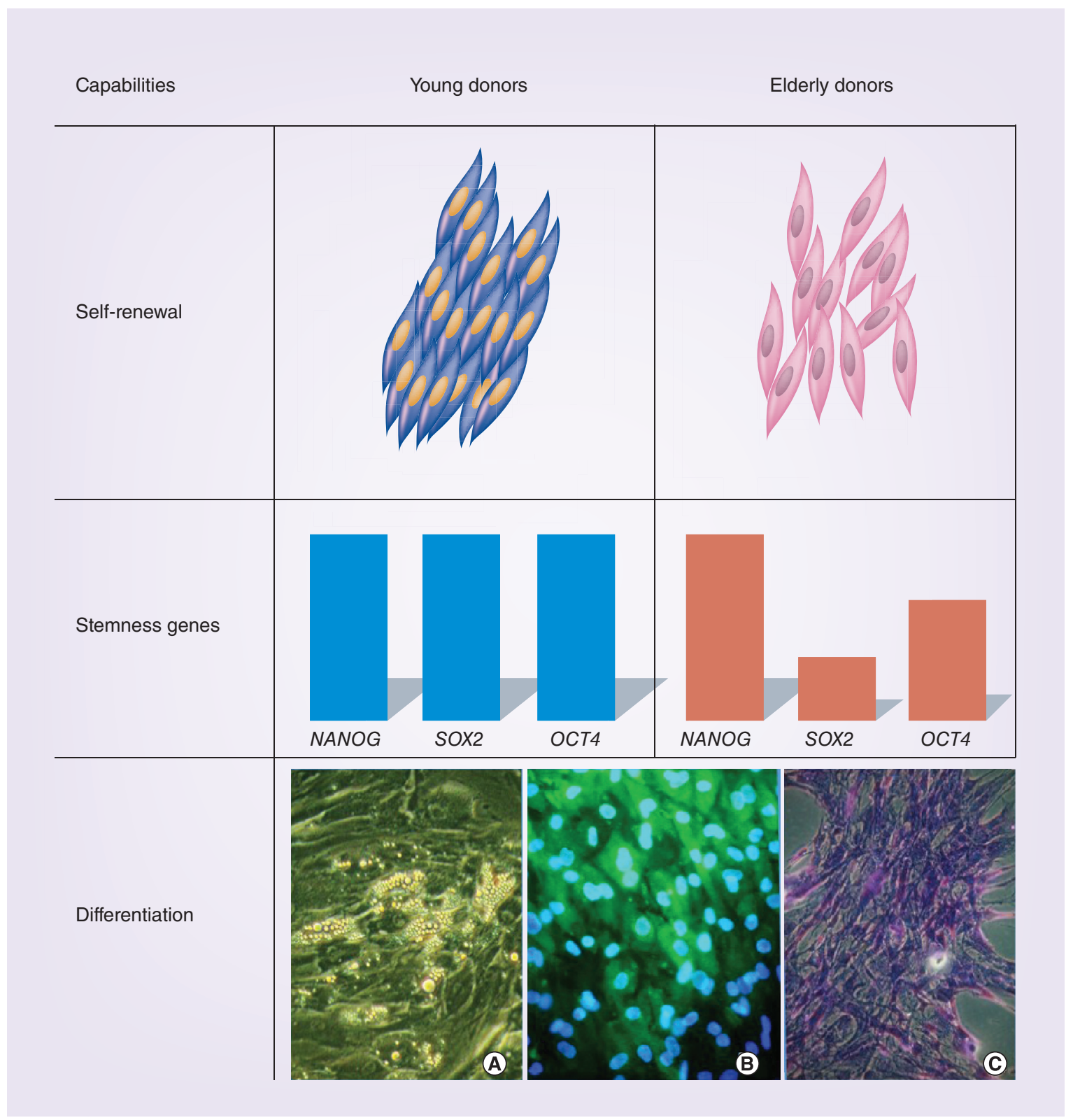

Figure 1. Comparisons of capabilities between mesenchymal stem cells obtained from young and old donors. Illustrative presentation of self-renewal capabilities: both cells present have the proliferative capacity, being high on cells from younger donators. Representative stemness genes expression: the expression of OCT4 and SOX2 decrease on cells from older donors. Differentiation: images of adipose-derived stem cells obtained in our laboratory from healthy donors and in vitro differentiate. Both sources of cells differentiate in vitro toward cells of mesodermal lineage. (A) Adipocytes showed intracellular lipid vacuoles. (B) Osteoblast showing osteocalcin (green) detected by immunofluorescent. (C) Chondroblast staining with Toluidine-blue for proteoglycans. 


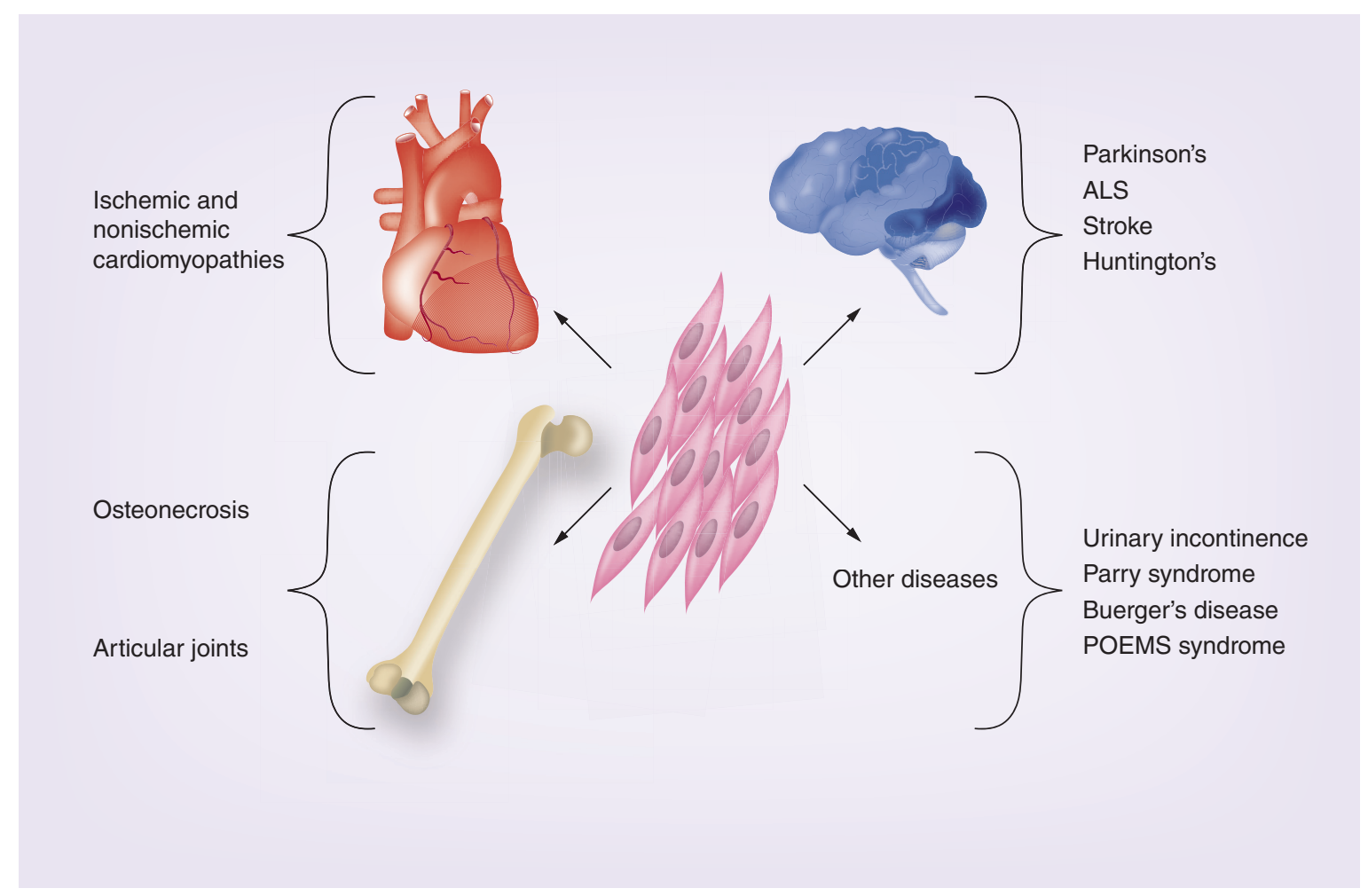

Figure 2. Clinical trials performed by autologous stem cells transplantation in older people. Degenerative diseases like cardiopathies and neuropathies, as well of loss of tissue or functionality, have shown some improve after transplantation.

ALS: Amyotrophic lateral sclerosis; POEMS: Polyneuropathy, organomegaly, endocrinopathy, M-protein or monoclonal gammopathy and skin changes.

tively accessible sources for adult stem cells are bone marrow, peripheral blood and adipose tissue. Samples from elderly people have been obtained, applied to autologous transplantation and have improved some degenerative diseases (Figure 2).

Examples of autologous transplantation applications for neurodegenerative diseases include ALS, Parkinson's disease, multiple sclerosis and Huntington's disease.

Patients with ALS who received harvested stem cells from the bone marrow or peripheral blood showed improved quality of life and survival [35-43].

Intra-arterial autologous implantation into the posterior region of the circle of Willis resulted in improvements in Parkinson's disease severity in patients greater than 60 years old [44]. The MSCs were transplanted into the sublateral ventricular zone during stereotaxic surgery to demonstrate the safety of the procedure. No adverse events were detected and some disease improvement was reported $[45,46]$.

Patients suffering from stroke have been treated with intravenous autologous transplantation of bone marrow mononuclear cells, but no beneficial effect of this treatment on stroke status outcome was reported. Nevertheless, the infusion-induced changes in the serum levels of GM-CSF, PDGF-BB and MMP-2 [47-50]. Patients transplanted with bone marrow aspirated and cultured MSCs have significantly reduced the clinical and functional deficits [51-54]. Important differences between those trials were the type of cells applied; in the first case, all cells were mononuclear in the sample whereas in the second case, the MSCs were selected by culture.

MSC transplantation in patients suffering from multiple sclerosis results in an immediate immunomodulatory effect. Using the mononuclear fraction prevents disease progression and improves scores on the the Extended Disability Status Scale [55,56].

The beneficial effects of autologous cell transplantation have been reported in patients with neurodegenerative diseases, including those performed on elderly patients. The stem cell subpopulations selected for treatment may have improved the outcomes.

Patients with POEMS syndrome (polyneuropathy, organomegaly, endocrinopathy, M-protein or monoclonal gammopathy and skin changes) have improvements in forced expiratory volume and total lung capacity after receiving mononuclear cells $[57,58]$ and nonhealing ulcers in patients with Buerger's disease treated with autologous bone marrow stem cells demonstrate accelerated healing [59]. Improvements in limb ischemia due to ischemic leg ulcers have also been reported [60-63]. 


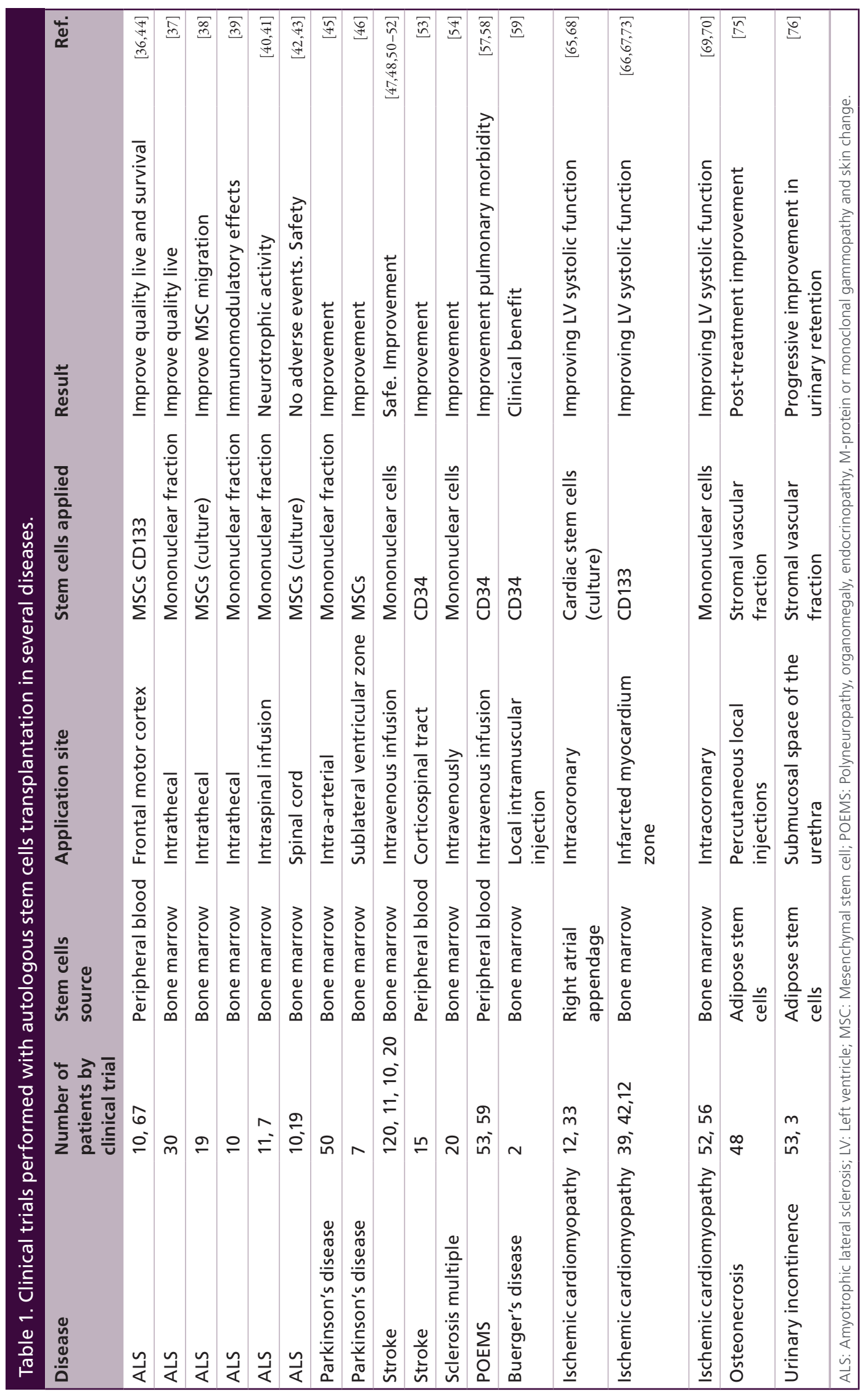


Numerous clinical trials have reported promising results using stem cells to revascularize patients with peripheral arterial disease [64].

Several clinical trials have been performed on ischemic and nonischemic cardiomyopathies in patients greater than 50 years old. The most promising among those trials included intracoronary infusion of mononuclear fractions of bone marrow-derived stem cells or MSCs from peripheral blood in patients suffering a myocardial infarction, in whom a moderate but significant improvement in left ventricular ejection volume was observed [65-72]. Transplantation of the specific stem cell fraction bearing $\mathrm{CD} 133^{+}, \mathrm{CD} 34^{+}$ or both antigens improves the quality of life after cell therapy in all cases [50,73,74]. There is no consensus about the best MSC subtype to treat ischemic heart disease [74]. Nevertheless, all studies in this area have reported improved cardiac function after autologous MSC transplantation.

Autologous ADSC transplantation has also been performed in elderly patients and autologous ADSCs have been injected safely into articular joints. Patients with osteonecrosis show post-treatment improvements [75]. In addition, patients with urinary incontinence treated with ADSCs showed progressive improvement in urinary retention capacity [76]. Similary, patients ( $>50$ years old) suffering from an abdominal aortic aneurysm improved after autologous ADSC transplantation [77]. Applications of autologous MSCs to treat various diseases and the results are summarized in Table 1.

\section{Discussion}

Stem cells obtained from elderly patients retain pivotal membrane cells markers, such as CD73, CD90 and CD105, and have in vitro self-renewal and differentiation capabilities in adipocytes, osteoblasts and chondroblasts. In addition, stem cells from elderly patients express the transcription factors responsible for cell proliferation, such as SOX2, NANOG and OCT4. Some reports have indicated that these genes are expressed at lower levels in elderly subjects than stem cells obtained from younger donors. Nevertheless, the cells respond to induced differentiation as

Executive summary

Stem cells in elderly patients

- Frequently, life expectancy is accompanied by an increase of degenerative diseases.

- Cell therapy offers the opportunity to regenerate the lost function.

- Autologous transplantation eliminates immune rejection and ethical concerns.

- There are some skeptical issues about the regenerative capacity of stem cells from elderly people.

Self-renewal capabilities

- When people become older, their number of stem cells decreases.

- In vitro, stem cells proliferation rates decrease.

- The number of stem cells harvests enough for cell transplantation.

Stemness gene expression

- Stem cells from elderly people express pluripotential genes.

- Expression of OCT4, NANOG and SOX2 genes declines.

- Nevertheless, these cells are capable of self-renewal.

In vitro differentiation

- Stem cells from elderly donors are capable of differentiating into adipocytes, osteoblasts and chondroblast lineage.

- Stem cells from elderly donors are capable of differentiating into neuronal lineage.

Clinical reports

- Several trials have been reported performing by autologous stem cells transplantation.

- In neurodegenerative diseases like amyotrophic lateral sclerosis, Parkinson's disease and Huntington's disease, autologous transplantations have shown an improvement of life quality.

- Autologous transplantation in patients suffering from myocardial infarction showed a significant improvement in the left ventricular ejection volume.

- Patients suffering from POEMS polyneuropathy, organomegaly, endocrinopathy, M-protein or monoclonal gammopathy and skin changes) syndrome showed an improvement in the patient-forced expiratory volume and total lung capacity.

- Patient with Buerger's disease showed an acceleration in the healing process.

- Patients with urinary incontinence showing progressive improvement in urinary retention capacity.

Conclusion

- Stem cells from elderly donors are capable of self-renewal and differentiation in vitro.

- Stemness genes expression decreases, but it is enough for self-renewal.

- Autologous transplantation in elderly patients increases life span and life quality. 
well as those obtained from younger donors. Several trials are currently being performed using autologous MSCs in elderly patients. Until more data are gathered indicating some beneficial effects, there is no consensus on the utility of stem cells as a gold standard treatment. Autologous bone marrow transplantation uses mobilized peripheral cells, ADSCs, mononuclear cells and their derived MSCs, or specific subpopulations, such as $\mathrm{CD} 34^{+}, \mathrm{CD} 133^{+}$and $\mathrm{CD} 271^{+}$cells. The variability in the results may be due to the different sources of MSCs, different techniques used to obtain cells, time placed outside the body or harmful additives, among other reasons. An in-depth analysis of the results based on the specific characteristics of the cells used is needed, as well as their application route.

\section{Conclusion}

Stem cells from elderly donors have similarly capabilities to growth and differentiation as younger donors.

\section{Future perspective}

Results obtained to date suggest that autotransplantation of MSCs is an important emerging therapy

\section{References}

Papers of special note have been highlighted as:

- of interest; $\bullet \bullet$ of considerable interest

1 Zuk PA, Zhu M, Ashjian P et al. Human adipose tissue is a source of multipotent stem cells. Mol. Biol. Cell 13(12), 4279-4295 (2002).

2 Jiang Y, Jahagirdar BN, Reinhardt RL et al. Pluripotency of mesenchymal stem cells derived from adult marrow. Nature 418(6893), 41-49 (2002).

3 Sakaguchi Y, Sekiya I, Yagishita K, Muneta T. Comparison of human stem cells derived from various mesenchymal tissues: superiority of synovium as a cell source. Arthritis Rheum. 52(8), 2521-2529 (2005).

4 Kerna S, Eichler H, Stoeve J, Klüte H, Bieback K. Comparative analysis of mesenchymal stem cells from bone marrow, umbilical cord blood, or adipose tissue. Stem Cells 24, 1294-1301 (2006).

5 Mariano ED, Teixeira MJ, Marie SK, Lepski G. Adult stem cells in neural repair: current options, limitations and perspectives. World J. Stem Cells 7(2), 477-482 (2015).

6 Scharstuhl A, Schewe B, Benz K, Gaissmaier C, Bühring H, Stoop R. Chondrogenic potential of human adult mesenchymal stem cells is independent of age or osteoarthritis etiology. Stem Cells 25(12), 3244-3251 (2007).

7 Cuevas-Diaz R, Gonzalez-Garza MT, Cardenas-Lopez A, Chavez-Castilla L, Cruz-Vega DE, Moreno-Cuevas JE. Age-related yield of adipose-derived stem cells bearing the for degenerative diseases in elderly patients with the advantage of eliminating possible immune rejection from heterologous transplant, ethical concerns or other unknown effects from using transformed cells. MSCs are safe and have demonstrated improvements in some degenerative disease conditions. Results from clinical trials suggest hope for therapies of disease with no effective therapy today.

\section{Financial \& competing interests disclosure}

The authors have no relevant affiliations or financial involvement with any organization or entity with a financial interest in or financial conflict with the subject matter or materials discussed in the manuscript. This includes employment, consultancies, honoraria, stock ownership or options, expert testimony, grants or patents received or pending, or royalties.

No writing assistance was utilized in the production of this manuscript.

\section{Open access}

This work is licensed under the Attribution-NonCommercialNoDerivatives 4.0 Unported License. To view a copy of this license, visit http://creativecommons.org/licenses/by-nc$n d / 4.0 /$

low-affinity nerve growth factor receptor. Stem Cells Int. 2013, 372164 (2013).

- Shows that stem cells in older donors express stemness gene and are self-renewal as younger donors.

8 Choudhery MS, Badowski M, Muise A, Pierce J, Harris DT. Donor age negatively impacts adipose tissue-derived mesenchymal stem cell expansion and differentiation. J. Transl. Med. 12, 8 (2014).

- Shows that stem cells in older donors express stemness gene and are self-renewal as younger donors.

9 Oreffo RO, Bennett A, Carr AJ, Triffitt JT. Patients with primary OA show no change with ageing in the number of osteogenic precursors. Scand. J. Rheumatol. 27(6), 415-424 (1998).

- Shows that stem cells in older donors express stemness gene and are self-renewal as younger donors.

10 Oreffo RO, Bord S, Triffitt JT. Skeletal progenitor cells and ageing human populations. Clin. Sci. (Lond.) 94(5), 549-555 (1998)

11 Ballas CB, Zielske SP, Gerson SL. Adult bone marrow stem cells for cell and gene therapies: implications for greater use. J. Cell. Biochem. Suppl. 38, 20-28 (2002).

12 Stenderup K, Justesen J, Clausen C, Kassem M. Aging is associated with decreased maximal life span and accelerated senescence of bone marrow stromal cells. Bone 33(6), 919-926 (2003).

13 Stenderup K, Rosada C, Justesen J et al. Aged human bone marrow stromal cells maintaining bone forming capacity 
in vivo evaluated using an improved method of visualization. Biogerontology 5(2), 107-118 (2004).

14 Bartunek J, Vanderheyden M, Vandekerckhove B et al. Intracoronary injection of CD133-positive enriched bone marrow progenitor cells promotes cardiac recovery after recent myocardial infarction: feasibility and safety. Circulation 112(Suppl. 9), I178-I183 (2005).

15 Siddappa R, Licht R, van Blitterswijk C, de Boer J. Donor variation and loss of multipotency during in vitro expansion of human mesenchymal stem cells for bone tissue engineering. J. Orthop. Res. 25(8), 1029-1041 (2007).

16 Stolzing A, Jones E, McGonagle D, Scutt A. Age-related changes in human bone marrow-derived mesenchymal stem cells: consequences for cell therapies. Mech. Ageing Dev. 129(3), 163-173 (2008).

17 Siegel G, Kluba T, Hermanutz-Klein U, Bieback K, Northoff $\mathrm{H}$, Schäfer R. Phenotype, donor age and gender affect function of human bone marrow-derived mesenchymal stromal cells. BMC Med. 11, 146 (2013).

18 Murphy JM, Dixon K, Beck S, Fabian D, Feldman A, Barry F. Reduced chondrogenic and adipogenic activity of mesenchymal stem cells from patients with advanced osteoarthritis. Arthritis Rheum. 46(3), 704-713 (2002).

19 Zhou S, Greenberger JS, Epperly MW et al. Age-related intrinsic changes in human bone-marrow-derived mesenchymal stem cells and their differentiation to osteoblasts. Aging Cell 7(3), 335-343 (2008).

20 Chakkalakal J, Brack A. Extrinsic regulation of satellite cell function and muscle regeneration capacity during aging. J. Stem Cell Res. Ther. Suppl. 11, 001 (2012).

21 Dominici M, Le Blanc K, Mueller I et al. Minimal criteria for defining multipotent mesenchymal stromal cells. The International Society for Cellular Therapy position statement. Cytotherapy 8(4), 315-317 (2006).

-. Establishes which characteristics cells must have in order to be considered as stem cells.

22 Gonzalez-Garza MT, Martinez HR, Caro-Osorio E, Cruz-Vega DE, Hernandez-Torre M, Moreno-Cuevas JE. Differentiation of $\mathrm{CD} 133^{+}$stem cells from amyotrophic lateral sclerosis patients into neuron-like cells. Stem Cell Transl. Med. 2(2), 129-135 (2013).

23 Cho GW, Noh MY, Kim HY, Koh SH, Kim KS, Kim $\mathrm{SH}$. Bone marrow-derived stromal cells from amyotrophic lateral sclerosis patients have diminished stem cell capacity. Stem Cells Dev. 19(7), 1035-1042 (2010).

24 Choumerianou DM, Martimianaki G, Stiakaki E, Kalmanti L, Kalmanti M, Dimitriou H. Comparative study of stemness characteristics of mesenchymal cells from bone marrow of children and adults. Cytotherapy 12(7), 881-887 (2010).

25 Pittenger MF, Mackay AM, Beck SC et al. Multilineage potential of adult human mesenchymal stem cells. Science 284(5411), 143-147 (1999).

26 D'Ippolito G, Schiller PC, Ricordi C, Roos BA, Howard GA. Age-related osteogenic potential of mesenchymal stromal stem cells from human vertebral bone marrow. J. Bone Miner. Res. 14(7), 1115-1122 (1999).
27 Zhou S, Bueno EM, Kim SW et al. Effects of age on parathyroid hormone signaling in human marrow stromal cells. Aging Cell 10(5), 780-788 (2011).

28 Bossolasco P, Cova L, Calzarossa C et al. Metalloproteinase alterations in the bone marrow of ALS patients. J. Mol. Med. 88(6), 553-564 (2010).

29 Ferrero I, Mazzini L, Rustichelli D et al. Bone marrow mesenchymal stem cells from healthy donors and sporadic amyotrophic lateral sclerosis patients. Cell Transplant. 17(3), 255-266 (2008)

30 Hermann A, List C, Habisch HJ et al. Age-dependent neuroectodermal differentiation capacity of human mesenchymal stromal cells: limitations for autologous cell replacement strategies. Cytotherapy 12(1), 17-30 (2010).

31 Zhang P, Moudgill N, Hager E et al. Endothelial differentiation of adipose-derived stem cells from elderly patients with cardiovascular disease. Stem Cells Dev. 20(6), 977-988 (2011).

32 Renault V, Thornell LE, Eriksson PO, Butler-Browne G, Mouly V. Regenerative potential of human skeletal muscle during aging. Aging Cell 1(2), 132-139 (2007).

33 Collins CA, Zammit PS, Ruiz AP, Morgan JE, Partridge TA. A population of myogenic stem cells that survives skeletal muscle aging. Stem Cells 25(4), 885-894 (2007).

34 Carlson ME, Suetta C, Conboy MJ et al. Molecular aging and rejuvenation of human muscle stem cells. EMBO Mol. Med. 1(8-9), 381-391 (2009).

- Shows that muscle satellite cells from a 70-year-old donor retain their potential.

35 Martinez HR, Gonzalez-Garza MT, Moreno-Cuevas JE et al. Stem-cell transplantation into the frontal motor cortex in amyotrophic lateral sclerosis patients. Cytotherapy 11(1), 26-34 (2009).

- Reports autologous stem cell transplantation is safe and feasible. Additionally, reports some benefice on the patients suffering from amyotrophic lateral sclerosis.

36 Deda H, Inci MC, Kürekçi AE et al. Treatment of amyotrophic lateral sclerosis patients by autologous bone marrow-derived hematopoietic stem cell transplantation: a 1-year follow-up. Cytotherapy 11(1), 18-25 (2009).

37 Karussis D, Karageorgiou C, Vaknin-Dembinsky A et al. Safety and immunological effects of mesenchymal stem cell transplantation in patients with multiple sclerosis and amyotrophic lateral sclerosis. Arch. Neurol. 67(10), 1187-1194 (2010).

38 Prabhakar S, Marwaha N, Lal V, Sharma RR, Rajan R, Khandelwal N. Autologous bone marrow-derived stem cells in amyotrophic lateral sclerosis: a pilot study. Neurol. India 60(5), 465-469 (2012).

39 Blanquer M, Pérez Espejo MA, Iniesta F et al. Bone marrow stem cell transplantation in amyotrophic lateral sclerosis: technical aspects and preliminary results from a clinical trial. Methods Find. Exp. Clin. Pharmacol. 32(Suppl. A), 31-37 (2010).

40 Blanquer M, Moraleda JM, Iniesta F et al. Neurotrophic bone marrow cellular nests prevent spinal motoneuron degeneration in amyotrophic lateral sclerosis patients: a pilot safety study. Stem Cells 30(6), 1277-1285 (2012). 
41 Mazzini L, Ferrero I, Luparello V et al. Mesenchymal stem cell transplantation in amyotrophic lateral sclerosis: a Phase I clinical trial. Exp. Neurol. 223(1), 229-237 (2010).

Mazzini L, Mareschi K, Ferrero I et al. Mesenchymal stromal cell transplantation in amyotrophic lateral sclerosis: a long-term safety study. Cytotherapy 14(1), 56-60 (2012).

43 Martinez HR, Molina-Lopez JF, Gonzalez-Garza MT et al. Stem cell transplantation in amyotrophic lateral sclerosis patients. Methodological approach, safety and feasibility. Cell Transplant. 21(9) 1899-1907 (2012).

44 Brazzini A, Cantella R, De la Cruz A et al. Intraarterial autologous implantation of adult stem cells for patients with Parkinson disease. J. Vasc. Interv. Radiol. 21(4), 443-451 (2010).

45 Martínez HR, Molina-Lopez JF, González-Garza MT et al. Stem cell transplantation in amyotrophic lateral sclerosis patients: methodological approach, safety, and feasibility. Cell Transplant. 21(9), 1899-1907 (2012).

46 Venkataramana NK, Kumar SK, Balaraju S et al. Openlabeled study of unilateral autologous bone-marrow-derived mesenchymal stem cell transplantation in Parkinson's disease. Transl. Res. 155(2), 62-70 (2010).

47 Prasad K, Mohanty S, Bhatia R et al. Autologous intravenous bone marrow mononuclear cell therapy for patients with subacute ischaemic stroke: a pilot study. Indian J. Med. Res. 136(2), 221-228 (2012).

48 Prasad K, Sharma A, Garg A et al. Intravenous autologous bone marrow mononuclear stem cell therapy for ischemic stroke: a multicentric, randomized trial. Stroke 45(12), 3618-3624 (2014).

49 Jimenez MD, Gil-Peralta A, Gonzalez A et al. Autologous intravenous bone marrow mononuclear cell therapy for patients with subacute ischaemic stroke: a pilot study. Indian J. Med. Res. 136, 221-228 (2012).

50 Moniche F, Montaner J, Gonzalez-Marcos JR et al. Intra-arterial bone marrow mononuclear cell (BM-MNC) transplantation correlates with GM-CSF, PDGF-BB and MMP-2 serum levels in stroke patients: results from a clinical trial. Cell Transplant. 23(Suppl. 1), 57-64 (2014).

51 Bhasin A, Srivastava MV, Kumaran SS et al. Autologous mesenchymal stem cells in chronic stroke. Cerebrovasc. Dis. Extra 1(1), 93-104 (2011).

- Reports autologous stem cell transplantation is safe and feasible. Additionally, reports some benefice on the patients suffering from stroke.

52 Moniche F, Gonzalez A, Gonzalez-Marcos JR et al. Intraarterial bone marrow mononuclear cells in ischemic stroke: a pilot clinical trial. Stroke 43(8), 2242-2244 (2012).

53 Chen DC, Lin SZ, Fan JR et al. Intracerebral implantation of autologous peripheral blood stem cells in stroke patients: a randomized Phase II study. Cell Transplant. 23(12), 1599-1612 (2014).

54 Bhasin A, Srivastava M, Bhatia R, Mohanty S, Kumaran $S$, Bose S. Autologous intravenous mononuclear stem cell therapy in chronic ischemic stroke. J. Stem Cells Regen. Med. 8(3), 181-189 (2012).
55 Mancardi GL, Sormani MP, Gualandi F et al. Autologous hematopoietic stem cell transplantation in multiple sclerosis: a Phase II trial. Neurology 84(10), 981-988 (2015).

- Multicenter, Phase II, randomized trial reports autologous stem cell transplantation on patients suffering from multiple sclerosis.

56 Blanco Y, Saiz A, Carreras E, Graus F. Autologous haematopoietic-stem-cell transplantation for multiple sclerosis. Lancet Neurol. 4(1), 54-63 (2005).

57 D'Souza A, Lacy M, Gertz M et al. Long-term outcomes after autologous stem cell transplantation for patients with POEMS syndrome (osteosclerotic myeloma): a single-center experience. Blood 120(1), 56-62 (2012).

58 Chandrashekaran S, Dispenzieri A, Cha SS, Kennedy CC. Pulmonary morbidity improves after autologous stem cell transplantation in POEMS syndrome. Respir. Med. 109(1), 122-130 (2015).

59 Boda Z, Razso K, Szarvas M et al. Repeated application of autologous bone marrow-derived stem cell therapy in patients with severe Buerger's disease. Stem Cell Disc. 1(1), 16-19 (2011).

60 Ishida A, Ohya Y, Sakuda H et al. Autologous peripheral blood mononuclear cell implantation for patients with peripheral arterial disease improves limb ischemia. Circ. J. 69(10), 1260-1265 (2005).

61 Gu Y, Zhang J, Qi L. A clinical study on implantation of autologous bone marrow mononuclear cells after bone marrow stimulation for treatment of lower limb ischemia. Zhongguo Xiu Fu Chong Jian Wai Ke Za Zhi. 20(10), 1017-1020 (2006).

62 Gu YQ, Zhang J, Guo LR et al. Transplantation of autologous bone marrow mononuclear cells for patients with lower limb ischemia. Chin. Med. J. 121(11), 963-967 (2008).

63 Moazzami K, Majdzadeh R, Nedjat S. Local intramuscular transplantation of autologous mononuclear cells for critical lower limb ischaemia. Cochrane Database Syst. Rev. 7(12), CD008347 (2011).

64 Botti C, Maione C, Coppola A, Sica V, Cobellis G. Autologous bone marrow cell therapy for peripheral arterial disease. Stem Cells Cloning 5, 5-14 (2012).

65 Bolli R, Chugh AR, D'Amario D et al. Cardiac stem cells in patients with ischaemic cardiomyopathy (SCIPIO): initial results of a randomised Phase I trial. Lancet 378(9806), 1847-1857 (2011).

- Autotransplant on the patients suffering from ischemic cardiomyopathy, reports improved function and no adverse effects were observed.

66 Yerebakan C, Kaminski A, Westphal B et al. Impact of preoperative left ventricular function and time from infarction on the long-term benefits after intramyocardial $\mathrm{CD}_{133(+)}$ bone marrow stem cell transplantation. J. Thorac. Cardiovasc. Surg. 142(6), 1530-1539 (2011).

67 Assmann A, Heke M, Kröpil P et al. Laser-supported $\mathrm{CD} 133^{+}$cell therapy in patients with ischemic cardiomyopathy: initial results from a prospective Phase I multicenter trial. PLoS ONE 9(7), e101449 (2014).

68 Chugh AR, Beache GM, Loughran JH et al. Administration of cardiac stem cells in patients with ischemic 
cardiomyopathy: the SCIPIO trial: surgical aspects and interim analysis of myocardial function and viability by magnetic resonance. Circulation 126(11 Suppl. 1), 54-64 (2012).

69 Assmus B, Schächinger V, Teupe C et al. Transplantation of progenitor cells and regeneration enhancement in acute myocardial infarction (TOPCARE-AMI). Circulation 106(24), 3009-3017 (2002).

70 Roncalli J, Mouquet F, Piot C et al. Intracoronary autologous mononucleated bone marrow cell infusion for acute myocardial infarction: results of the randomized multicenter BONAMI trial. Eur. Heart J. 32(14), 1748-1757 (2011).

71 Delewi R, Hirsch A, Tijssen JG et al. Impact of intracoronary bone marrow cell therapy on left ventricular function in the setting of ST-segment elevation myocardial infarction: a collaborative meta-analysis. Eur. Heart J. 35 (15), 989-998 (2014).

72 Stamm C, Kleine HD, Choi YH et al. Intramyocardial delivery of $\mathrm{CD} 133^{+}$bone marrow cells and coronary artery bypass grafting for chronic ischemic heart disease: safety and efficacy studies. J. Thorac. Cardiovasc. Surg. 133(3), 717-725 (2007).
73 Manginas A, Goussetis E, Koutelou M et al. Pilot study to evaluate the safety and feasibility of intracoronary CD133( $\left(^{+}\right)$and $\mathrm{CD} 133\left(^{-}\right) \mathrm{CD} 34\left(^{+}\right)$cell therapy in patients with nonviable anterior myocardial infarction. Catheter Cardiovasc. Interv. 69(6), 773-881 (2007).

74 Dixit P, Katare R. Challenges in identifying the best source of stem cells for cardiac regeneration therapy. Stem Cell Res. Ther. 6, 26 (2015).

75 Pak J, Chang JJ, Lee JH, Lee SH. Safety reporting on implantation of autologous adipose tissue-derived stem cells with platelet-rich plasma into human articular joints. $B M C$ Musculoskelet. Disord. 14, 337 (2013).

76 Yamamoto T, Gotoh M, Kato M et al. Periurethral injection of autologous adipose-derived regenerative cells for the treatment of male stress urinary incontinence: report of three initial cases. Int. J. Urol. 19(7), 652-659 (2012).

77 Parvizi M, Harmsen MC. Therapeutic prospect of adiposederived stromal cells for the treatment of abdominal aortic aneurysm. Stem Cells Dev. 24(13), 1493-1505 (2015). 